\title{
A Fundamentação Ética dos Direitos Humanos em John Finnis
}

\author{
Victor Sales Pinheiro \\ Professor-adjunto da Universidade Federal do Pará (UFPA). \\ Coordenador do Grupo de Pesquisa (CNPq) "Tradição da \\ Lei Natural". Doutor em Filosofia pela Universidade do \\ Estado do Rio de Janeiro (Uerj). Mestre em Filosofia pela \\ Pontifícia Universidade Católica do Rio de Janeiro (PUC- \\ -RIO). Graduado em Direito no Centro Universitário do \\ Estado do Pará (Cesupa).vvspinheiro@yahoo.com.br.
}

\section{Elden Borges Souza}

Mestrando em Direito pelo Programa de Pós-Graduação em Direito (PPGD) da Universidade Federal do Pará (UFPA). Bacharel em Direito pelo Centro Universitário do Estado do Pará (Cesupa). Bolsista da Coordenação de Aperfeiçoamento de Pessoal de Nível Superior (Capes). Pesquisa desenvolvida no Grupo de Pesquisa (CNPq) "Tradição da Lei Natural”. elden.borges@gmail.com.

\begin{abstract}
Resumo
Formado na teoria analítica do Direito, Finnis percebeu a falsa compreensão acerca do Direito Natural presente nesta tradição. A partir disso, seu principal mérito foi ter demonstrado o caráter infundado da resistência positivista à teoria do Direito Natural. A tese central desta teoria é a da existência, racionalmente cognoscível, de uma lei cuja normatividade independe da autoridade política ou da lei positiva. A teoria de Finnis também destaca o papel dos bens básicos para o florescimento humano. Nesse sentido, o objetivo do presente trabalho é analisar a teoria da lei natural em Finnis, buscando introduzir seu pensamento no debate acerca da fundamentação ética dos direitos humanos.
\end{abstract}

Palavras-chave: John Finnis. Lei natural. Direitos humanos. 


\title{
THE ETHICAL FOUNDATION OF HUMAN RIGHTS IN JOHN FINNIS
}

\begin{abstract}
Formed in the analytical jurisprudence, Finnis realized the false understanding of Natural Law present in this tradition. From this, his main merit was to have demonstrated the unfounded nature of the positivist resistance to the theory of Natural Law. The central thesis of this theory is the existence, rationally knowable, a law whose normativity independent of political authority or positive law. Finnis' theory also highlights the role of basic goods for human flourishing. In this sense, the objective of this study is to analyze the theory of natural law in Finnis, seeking to introduce his thought in the debate about the ethical foundation of human rights.
\end{abstract}

Keywords: John Finnis. Natural law. Human rights.

\section{Sumário}

1 Introdução. 20 Contexto de John M. Finnis. 3 Dimensão Metodológica da Teoria. 4 Dimensão Substancial da Teoria. 5 Conclusão. 6 Referências. 


\section{INTRODUÇÃO}

Até o início da Idade Moderna é difícil identificar uma oposição mutuamente excludente entre o Direito Positivo e o Direito Natural - isso, para não afirmar inexistente essa contradição. A Antígona de Sófocles nos mostra que já na Antiguidade era possível identificar o conflito entre a lei positiva e a lei natural. Isso, no entanto, não significava que a existência do Positivo, por si, afastava a existência do Direito Natural.

A tradição aristotélico-tomista consolidada sustentava uma relação de coordenação entre as duas leis - e não uma visão de oposição. Até o final da Idade Média, portanto, é possível identificar a importância do Direito Positivo, que, no entanto, não pode negar a lei natural - como tentou fazer Creonte em Tebas. Essa relação não somente era importante ou útil, era indispensável.

O gesto moderno inicial, contudo, foi de dissociar o Direito Natural do Direito Positivo. O racionalismo reinante separa a lei natural do contexto histórico e cultural, defendendo um idealismo. Essa concepção acarretou críticas ao conceito de "natureza”, persistentes até a contemporaneidade.

Um segundo gesto leva à defesa da supressão do Direito Natural. Se a Modernidade é o reino da razão, representa igualmente o triunfo da vontade humana. Conjugadas, razão e vontade transformam o Direito em lei humana, pois o homem - enquanto ser racional - é capaz de decidir e escolher a quais leis desejar estar submetido. O ser humano não precisa mais estar submetido às forças da natureza ou a uma ordem dada - seja de natureza cosmológica ou teológica. Agora o homem pode dominar a natureza, inclusive determinando todas as leis que vai seguir.

A tradição da lei natural, então, é abandonada e relegada a um elemento histórico, sem força sobre o conceito moderno de Direito. A banalidade do mal, no entanto, para usar uma expressão de Hannah 
Arendt (1999), concretizada ao longo do século 20, em estrita observância à legalidade, retoma a incômoda pergunta sobre os limites do Direito Positivo.

Finnis é um dos defensores desse movimento de reafirmação da tradição clássica da lei natural. Sua obra possui uma dimensão metodológica e uma dimensão substancial que serão apresentadas ao longo deste trabalho. Merece destaque que a posição de Finnis identifica que o homem deve florescer, isto é, deve alcançar a plenitude. Para isso, alguns bens básicos devem ser buscados pelas pessoas e, por consequência, devem ser assegurados a elas.

Nesse contexto, a pergunta central acerca dos direitos humanos conduz ao pensamento de Finnis: Qual a finalidade desses direitos? Enquanto o positivismo jurídico volta-se à estrutura da norma, a teoria clássica da lei natural questiona a teleologia. Se os direitos humanos são mais do que a decisão de um corpo legislativo nacional ou internacional, então eles não podem ser suficientemente explicados pela teoria positiva do Direito. É necessário, portanto, uma teoria que estruture bens necessários ao florescimento humano.

Partindo da insuficiência do positivismo jurídico - que, em razão dos limites deste trabalho, será tomada como pressuposta -, o objetivo da presente pesquisa é apresentar a teoria de John Finnis e como ela permite sustentar a concepção contemporânea de direitos humanos. Para isso, será apresentado o contexto teórico no qual Finnis está inserido e, posteriormente, as dimensões metodológica e substancial de sua teoria, que sustentam a possibilidade de uma fundamentação ética desses direitos.

\section{O CONTEXTO DE JOHN M. FINNIS}

O jusfilósofo John Finnis doutorou-se com Hart, em 1965, em Oxford. A pedido do seu célebre professor positivista, Finnis dedica-se, durante a década de 70, à redação da sua obra-prima, Lei natural e direitos naturais, de 1980 publicado no Brasil, pela Editora Unisinos apenas em 2007 (Finnis, 2007b). 
Formado na teoria analítica do Direito, que tem em Hart seu eixo central, Finnis percebeu a falsa compreensão acerca do Direito Natural presente nesta tradição, sobretudo quando estudou a tradição realista, de Aristóteles e Tomás de Aquino. Seu mérito principal foi ter demonstrado o caráter infundado da resistência positivista à teoria do Direito Natural, até então estigmatizada como obscurantismo religioso e supersticioso.

Depois da obra-prima citada, Finnis continuou sua atividade acadêmica de forma intensa, publicando: Fundamentos de Ética, de 1983, editada no Brasil pela editora Elsevier (Finnis, 2012); Moral Absolutes (Finnis, 1991) e, mais recentemente, Aquinas: Moral, Political and Legal Theory (Finnis, 1998). Além desses quatro livros centrais, Finnis tem a sua obra reunida publicada em cinco volumes pela Universidade de Oxford, com centenas de artigos em que enfrenta a teoria e a prática da lei natural.

Dessa miríade de ensaios podem-se mencionar quatro textos, publicados no Brasil: o verbete intitulado "Lei Natural. Por que chamar de 'lei'? Por que dizê-la 'natural'?”, do Dicionário de Ética e Filosofia Moral (Finnis, 2013); os artigos "Filosofia Moral, Política e Jurídica em Tomás de Aquino" e "Teorias do Direito Natural", compilados no volume Direito Natural em Tomás de Aquino: sua reinserção no contexto do juspositivismo analítico (Finnis, 2007a), e o artigo "Revisitando os fundamentos da razão prática”, constante de Correntes contemporâneas do pensamento jurídico (Finnis, 2010).

O trabalho empreendido por Finnis de recolocar no debate jurídico a questão do Direito Natural não se encerra com sua obra. Ao contrário, a obra de Finnis passa a ser debatida e comentada e, a partir dela, o jusnaturalismo assume uma posição de destaque nos debates jurídico, político e ético - tanto nos países de tradição filosófica analítica, quanto naqueles de tradição filosófica continental. 
Enquanto as discussões das quais Finnis participa concentram-se nos aspectos ético e jurídico da lei natural, seus comentadores vão destacar também a dimensão política da lei natural. George (1999), por exemplo, após um incurso nas questões teoréticas da Nova Teoria do Direito Natural, passa a debater as implicações práticas - morais e políticas - da lei natural, como o casamento, a pornografia e o aborto.

Por outro lado, considerando que Finnis não esgotou o debate com o positivismo jurídico, outros adeptos de sua posição vão enfrentar questões jurídicas da lei natural, como a de validade. Nesse contexto, Murphy (2006) assume a responsabilidade de apresentar as diversas concepções acerca da relação entre a lei natural e a lei positiva, o bem comum e a questão da autoridade.

Todo esse debate não ficou afastado do Brasil, país no qual Finnis foi introduzido por, pelo menos, dois autores. Oliveira (2002) apresenta o bem comum na tradição tomista encampada por John Finnis e a discussão ao redor deste tema. Já Barzotto (2010) é responsável por um debate mais plural. Em sua obra, Finnis é inserido em uma tradição muito maior, cujos expoentes máximos, Aristóteles e Aquino, não podem ser subestimados.

Assim sendo, a (Nova) Teoria da Lei Natural defendida por Finnis adquiriu uma relevância que exige um debate maior, principalmente no contexto jurídico brasileiro.

\section{DIMENSÃO METOdOLÓGICA DA TEORIA}

A primeira parte de Lei natural e direitos naturais (Finnis, 2007b) é dedicada a uma elucidação metodológica preliminar, que apresenta os fundamentos epistemológicos da teorização de Finnis. Por essa razão, convém sublinhar seus pontos centrais. 
O Direito é uma instituição social que permite a realização de bens humanos e da razoabilidade prática com que os homens os decidem. $\mathrm{O}$ objetivo do livro é, então, triplo: (i) identificar os bens humanos básicos (aspecto substantivo da teoria); (ii) analisar a razoabilidade prática que os efetiva na ação humana, na vida prática (aspecto prudencial da teoria) e (iii) elucidar a epistemologia adequada à compreensão do Direito.

No terceiro item Finnis afirma a vinculação indissociável dos processos de descrição e avaliação na metodologia de toda ciência social. Dessa forma, ele une a premissa positivista da descrição à premissa jusnaturalista da avaliação do Direito, pois "um teórico não pode fornecer uma descrição teórica e uma análise de fatos sociais, a menos que também participe do processo de avaliar, de entender o que é realmente bom para as pessoas humanas e o que é realmente requerido pela razoabilidade prática” (Finnis, 2007b, p. 17).

Ora, uma ciência social, como a ciência do Direito (também denominada dogmática jurídica ou jurisprudência analítica) e a Sociologia, tem como objeto ações e discursos práticos dos homens, os quais só podem ser compreendidos pelos propósitos, pelos fins a que se destinam. Essa noção de razão prática que desponta nas primeiras linhas de Finnis evidencia a dimensão teleológica de seu pensamento. A teleologia refere-se ao telos, ao fim da ação, ao bem a que ela se volta como objetivo: o propósito que responde pela causa final da ação.

Convém ressaltar, desde já, que a noção de "prático" em Finnis relaciona-se à ação e à decisão que a antecede, e não diz respeito à praticidade enquanto factibilidade ou eficiência. Prático aqui, no sentido aristotélico que Finnis emprega esse termo, não é oposto ao intelectual, ao reflexivo ou ao teórico. Da mesma forma, razoabilidade prática significa decidir, assumir compromissos, eleger projetos e executá-los, em uma palavra, “agir”, e não apenas "fazer" (no sentido técnico do termo, da obediência irrefletida a um método predeterminado que não deixa margem à delibe- 
ração, como a instalação de uma mesa). Por isso, a razão prática é indissociável do processo deliberativo que gestou a ação e do seu resultado final (telos) (Finnis, 2007b, p. 25).

Como pensar, então, uma teoria geral descritiva da ação humana diante da irredutível variabilidade pessoal, social, geográfica e histórica de condutas humanas e discursos que as explicam? A ciência do Direito seria apenas uma listagem descritiva dessas ações? Finnis responde negativamente a essa última questão: pela dimensão teleológica que a caracteriza, a ciência do Direito não se limita a uma mera conjunção de lexicografia (de termos que explicam as ações humanas) da história local, ou uma justaposição de todas as lexicografias conjugadas às histórias locais (Finnis, 2007b, p. 18).

Criticando a ingenuidade do método dos primeiros juristas analíticos, os iniciadores da ciência positivista do Direito, Bentham, Austin e Kelsen, Finnis apoia-se na sofisticação do método analítico de Hart e Raz para afastar o "ponto de vista externo", na expressão de Elton Oliveira (2002, p. 32). Trata-se do ponto de vista neutro e avalorativo, em que o cientista descreve o fato social como se não estivesse, de alguma forma, implicado nele. As análises descritivas de Hart e Raz têm um poder explicativo superior às dos primeiros positivistas por três características principais: (i) atenção ao propósito prático; (ii) seleção do caso central e significado focal e (iii) seleção do ponto de vista.

O princípio teleológico da razão prática (i) já foi esclarecido anteriormente: toda descrição social aponta para a finalidade prática dos elementos que constituem a descrição. Para investigar essa finalidade prática, Finnis adota o instrumento filosófico aristotélico da analogia para distinguir casos perfeitos de casos imperfeitos. Assim, ele identifica um "significado focal", que lhe fornece um critério para uma descrição especificamente jurídica, diferente das demais descrições sociais. Qual é, porém, o objeto tipicamente jurídico? Pode-se perguntar, ainda: O que é o Direito? 
Para responder a essa pergunta Finnis recorre à distinção analógica entre caso central e casos periféricos (ii). $\mathrm{O}$ caso central é o significado focal, a realidade nua e crua, sem atenuantes ou agravantes, considerada em si mesma. Por outro lado, os casos periféricos dizem respeito aos significados secundários, ou seja, a realidade enfocada a partir de certo aspecto, nuançada por determinada perspectiva. Para determinar o caso central, deve-se perguntar pelas razões e motivos da ação jurídica, imergindo no ambiente social em análise, de um ponto de vista interno (iii). Só assim se pode determinar o que é verdadeiramente importante e significativo no objeto estudado, seu caso central. O reconhecimento do caráter heurístico do ponto de vista interno já figura na obra de Hart (2009), para quem o teórico do Direito avalia a sua própria conduta e a dos demais a partir das regras estudadas.

Eis como Finnis (2007b, p. 25) sintetiza o argumento exposto:

Pensamento prático é pensar a respeito do que (se deve) fazer. Razoabilidade prática é razoabilidade na decisão, na adoção de compromissos, na escolha e na execução de projetos e, em geral, na ação. A filosofia prática é uma reflexão disciplinada e crítica sobre os bens que podem ser realizados na ação humana e nos requisitos da razoabilidade prática. Então, quando dizemos que o teórico descritivo (cujos propósitos não são práticos) deve agir, em sua seleção e formação indispensável de conceitos, adotando um ponto de vista prático, queremos dizer que ele deve avaliar a importância ou o alcance das semelhanças e diferenças em seu assunto perguntando o que seria considerado importante ou significativo nesse campo por aqueles cujas preocupações, decisões e atividades criam ou constituem $o$ assunto.

Como é possível perceber, a perspectiva interna de análise do Direito concerne à razoabilidade prática, aos motivos da ação e aos critérios de sua avaliação. Finnis define o caso central do Direito como sendo o Direito Positivo, pois este é fruto do trabalho humano e dotado de obrigatoriedade. Com isso, ele afasta-se de concepções tradicionais do Direito 
Natural que entendem ser a coisa ou a conduta justa o caso central de Direito, aproximando-se das teorias positivistas de Hart e Raz, que procedem à análise jurídica da norma positiva.

Deve-se notar que Finnis não será nem um legalista "puro”, nem um jusnaturalista desatento à realidade jurídica positivada, mas isso ficará claro quando, determinado o Direito Positivo como caso central da análise, se entender o papel desempenhado pelo Direito Natural nessa articulação.

O Direito Natural será o caso periférico do método, o caso que permite avaliá-lo, julgá-lo, nuançá-lo, compará-lo, hierarquizá-lo. Ou seja, o direito natural (caso periférico) será o critério do Direito Positivo (caso central). O Direito Natural não é resultado do trabalho humano e sua obrigatoriedade independe da sanção política. Finnis conceitua os direitos naturais como o conjunto de princípios de razoabilidade prática que ordena a vida e a comunidade humanas. Isto é, o Direito Natural identifica-se com a moral e a razoabilidade prática. Por essa razão é que se pode defender a hipótese central desta análise: a de que é possível fundamentar os diretos humanos na lei natural e na razão prática, nos casos periféricos do Direito que servem de critérios avaliativos para os direitos humanos positivados (caso central).

Em texto recente, Finnis formula novamente essa questão: "As teorias gerais do Direito podem ser livres de valores?” Nele, o filósofo explica o caráter inevitável do ponto de vista interno, assim como a impossibilidade metodológica do ponto de vista meramente externo. Ou seja, a rejeição do ponto de vista externo, neutro e não valorativo, tal como apregoado pelo positivismo, se dá em nome da adoção de um ponto de vista teleológico e prático, da perspectiva interna que investiga as razões morais e jurídicas pelas quais os homens agem de certo modo. Nesse sentido, Finnis (2007a, p. 115) abona a crítica que L. Green (2015) faz à pretensão positivista de uma separação rígida entre Direito e moral: 
O argumento avaliativo é naturalmente central para a filosofia do direito em geral. Nenhum filósofo do direito pode ser apenas um juspositivista. Uma teoria completa do direito requer também uma observação sobre que tipo de coisas poderiam possivelmente figurar como méritos da lei (a lei deveria ser tão eficiente ou refinada, quanto justa?); sobre qual o papel a lei deveria ter no julgamento (leis válidas deveriam ser sempre aplicadas?); sobre que obediência a lei exige de nós (existe um dever de obedecer?); e também sobre as perguntas basilares sobre quais leis nós devemos ter e de se deveríamos ter leis. $\mathrm{O}$ juspositivismo não aspira responder estas questões, embora suas exigências a respeito da existência e conteúdo da lei dependam somente dos fatos sociais lhes dando forma.

Com a adoção do raciocínio analógico que distingue casos perfeitos dos imperfeitos, Finnis articula a razão prática com a ciência social descritiva de modo ímpar no contexto do pensamento jurídico contemporâneo. Com efeito, ele reconhece haver um virtuoso movimento pendular de vaivém "entre, por um lado, avaliações do bem humano e de seus requisitos práticos e, por outro lado, descrições explanatórias (...) do contexto humano no qual o bem-estar humano é realizado e arruinado de inúmeras maneiras" (Finnis, 2007a, p. 30).

Finnis explica que não se trata de inferir bens humanos (no plano de dever-ser) de fatos sociais (no plano do ser) - o que recairia na falácia naturalista (2013, p. 605) -, tampouco de reduzir "uma ciência social descritiva a uma apologia de juízos éticos ou políticos” (2013, p. 605). Não se trata, portanto, de confundir razão prática e ciência social descritiva, mas de perceber a dimensão teleológica e prática da ciência social descritiva, alcançando um “equilíbrio reflexivo”, uma virtude que se dá apenas mediante:

Grande conhecimento dos dados e um penetrante entendimento dos pontos de vista e das preocupações práticas de outros homens (...) aliados a um sólido juízo a respeito de todos os aspectos do genuíno florescimento humano e da autêntica razoabilidade prática dos seres humanos (Finnis, 2013, p. 605). 
Ao lado da dimensão metodológica da teoria de Finnis - que já indica a diferença para o positivismo jurídico - coexiste uma dimensão substancial, que retoma claramente a concepção aristotélico-tomista do Direito.

\section{DIMENSÃO SUBSTANCIAL DA TEORIA}

Deve-se, agora, estudar os bens humanos básicos que permitem o florescimento humano (dimensão substancial da teoria), que, segundo a hipótese central deste texto, servem de fundamento ético dos direitos humanos.

$\mathrm{Na}$ ordem do conhecimento prático, ou moral, deve-se adotar um método correspondente, capaz de conhecer o sentido da ação humana, a que ela se dirige, o seu bem. Esse método é o teleológico, a investigação dos bens humanos básicos cuja consecução realiza a natureza humana.

A relação entre natureza humana e bens humanos básicos deve ser compreendida, do ponto de vista ontológico e epistemológico, por um conhecido teorema de Aristóteles (2013, II, 4, 415a, 16-21), que afirma: para compreender a natureza de um ser animado, deve-se compreender as suas faculdades (potências); para compreender suas faculdades, deve-se compreender as suas ações (morais); para compreender suas ações, deve-se compreender os fins dessas ações, seus objetos ou propósitos (telos). Esses fins são chamados, por Aristóteles, desde o princípio de sua Ética a Nicômaco (2001), de bens, cuja consecução realiza a felicidade (eudaimonia).

A Filosofia prática, portanto, volta-se ao conhecimento dos bens humanos básicos, os quais permitem o florescimento das capacidades naturais do homem. Como explicam Culleton, Bragato e Fajardo (2009, p. 47), na discussão da fundamentação dos direitos humanos a partir da lei natural em Finnis, os bens humanos básicos "são bens fundamentais a que 
a vontade visa, ou seja, os bens que constituem nossas razões fundamentais para agir e que dão conta de tudo o que podemos inteligentemente querer escolher”.

A ética aristotélica só pode ser plenamente compreendida quando relacionada a sua metafísica. A noção de florescimento humano é teleológica e pode ser explorada pelos conceitos de ato e potência. Como ser vivo, o homem é dotado de faculdades naturais (potências), que podem ou não ser realizadas, colocadas em ato. A ação virtuosa é exatamente a ação que atualiza (coloca em ato) uma potência natural, antes latente em estado de potência.

A metáfora botânica é propícia para entender esse binômio filosófico de ato e potência. Quando uma flor recebe as condições ambientais necessárias - como terra fértil, água e ar -, ela floresce, isto é, vem a ser efetivamente o que ela já era apenas como potência. Uma semente é uma flor em potência, que depende de condições ideais para florescer e alcançar, em ato, o fim potencial a que se destina por natureza. Os bens humanos básicos são as formas elementares de florescimento humano, bens que são universalmente buscados e realizados por todos que refletem e deliberam sobre o que fazer, ainda que sejam infundadas as suas conclusões (Culleton; Bragato; Fajardo, 2009, p. 47).

No estudo da ação humana (ética ou filosofia prática), investiga-se como se forma o juízo moral, o processo deliberativo que leva à conduta. A razoabilidade prática é a justificação das boas razões de determinado ato. Essas boas razões são os bens básicos a que elas, invariavelmente, se voltam. Esses bens são autoevidentes, por isso indemonstráveis, objetivos, universais, irredutíveis e não hierarquizáveis entre si.

Com isso, alija-se todo tipo de relativismo axiológico, à revelia da aparente irredutibilidade e diversidade dos valores morais. Como a literatura antropológica mais recente revela, há uma sólida unanimidade a respeito desses bens, que permite identificá-los de modo consistente 
(Finnis, 2007b, p. 89). Núcleo da razão prática, eles servem para a inteligibilidade da ação, isto é, para torná-la compreensível e razoável à comunidade humana em geral. Servem para motivar as ações, como "indicadores (bússolas) para o raciocínio moral” (Engelman, 2007, p. 154). Os bens humanos básicos são critérios de avaliação da ação moral, são princípios práticos evidentes e indemonstráveis, que informam a razão prática, que se pergunta pelos bons motivos para agir. São esses motivos que tornam a ação inteligível, compreensível, razoável. Para exemplificar de modo convincente a natureza evidente e universal dos bens básicos, Finnis (2007b, p. 67-81) apresenta o bem do conhecimento. É inegável que o conhecimento é mais desejável do que a ignorância. Enquanto ausência de conhecimento, a ignorância aponta para a sua superação, revela-se condição (potência) para o conhecimento (ato). Ora, o florescimento humano depende do desenvolvimento da capacidade cognitiva, e isso é universal e inquestionável. Pode-se distinguir o conhecimento instrumental (com vistas a um fim que o transcende) do conhecimento especulativo-teórico (como um fim em si mesmo). Em relação à curiosidade natural, facilmente observável em qualquer homem, diz-se que “é bom conhecer”, independentemente da utilidade derivada do conhecimento.

Após esse exemplo do conhecimento, o primeiro valor básico é, naturalmente, a vida, que diz respeito ao impulso de autoconservação, envolvendo todas as ações relacionadas à saúde (Finnis, 2007b, p. 91-92). O bem da vida aqui é a "boa forma para a autodeterminação". Como todo bem humano básico, a vida é um valor inquestionável e irrefutável, pois, sem vida, o florescimento humano não seria possível, a atualização das potências fundamentais seria impensável. A vida pressupõe, então, continuar a viver, não ser privado do direito a nascer e a preservar-se saudável a ponto de perseguir seus fins últimos. 
Depois da vida e do conhecimento, o terceiro bem humano básico é o jogo, isto é, o engajamento social do homem, que, para ser plenamente humano, pertence e participa de uma comunidade. São atividades desempenhadas como fins em si mesmas; trata-se de um conceito abrangente, pois o jogo pode ser "solitário ou social, intelectual ou físico, tenso ou relaxado, altamente estruturado ou relativamente informal, convencional ou de padrão ad hoc...” (Finnis, 2007b, p. 92-93).

A quarta forma fundamental de bem é a experiência estética (Finnis, 2007b, p. 93). Embora a noção de jogo envolva uma dimensão de contemplação estética, como no caso da dança, da música, do esporte, essa categoria de bem não depende da ação humana diretamente, podendo se dar, por exemplo, com a contemplação da própria natureza.

Em quinto lugar, há o bem da sociabilidade (Finnis, 2007b, p. 93). Ora, como o homem é um animal político, segundo a clássica definição de Aristóteles, é impossível que ele não se relacione com os homens da cidade a que pertence. A sociedade é composta exatamente da harmonização das ações individuais em vista do bem comum. $\mathrm{O}$ vínculo mínimo e necessário de paz e harmonia entre os homens que convivem numa mesma organização política é o bem da sociabilidade, que, passando por todas as formas de comunidade humana, desabrocha na amizade plena, cuja relação não é mais instrumental, impessoal e meramente funcional, mas intrínseca e profunda.

O sexto bem humano básico é a razoabilidade prática, que é a capacidade de "utilizar com eficiência a inteligência (no raciocínio prático que resulta em ação) nos problemas de escolher as ações, o estilo de vida e de dar forma ao caráter” (Finnis, 2007b, p. 93). Trata-se de um bem básico complexo, que envolve liberdade e razão, integridade e autenticidade, ou seja, da tentativa de imprimir uma ordem inteligente e razoável à con- 
duta, gozando de liberdade de escolha e determinação, superando estados passivos de doutrinação social e agindo com responsabilidade diante dos princípios racionais que estruturam a vida.

O sétimo valor básico é a religião, universalmente presente em todas as sociedades humanas (Finnis, 2007b, p. 94). Com esse bem, Finnis não pensa em nenhuma organização responsável pelo contato com a dimensão divina da realidade (Dias, 2013, p. 145), mas da existência inquestionável de indagações metafísicas em relação à ordem que ultrapassa por completo o campo da experiência individual, alcançando a origem do cosmos, da liberdade humana e da razão. Isto é, a preocupação com a ordem de coisas "além” de cada um.

Esse bem resiste a uma crítica agnóstica ou materialista, assim como a qualquer tipo de negativismo antirreligioso, uma vez que independe da crença em uma religião positiva específica. Mencionando o ateísmo de Sartre, Finnis (2007b, p. 95) demonstra que a especulação metafísica sobre uma ordem supraindividual e irredutível à experiência sensível é universal, pois mesmo um ateu como Sartre - que seria um exemplo emblemático da verdade desse bem - reconhece ser a liberdade um fator de limitação do árbitro e que, portanto, há certa essência livre que caracteriza sua condição ou natureza, que o torna responsável.

Embora essa lista de sete bens básicos não seja exaustiva, eles compõem, em conjunto, "a totalidade dos propósitos básicos da ação humana" (Finnis, 2007b, p. 97), capazes de subsumir, como categorias gerais, qualquer outro fim humano. Esses bens são independentes uns dos outros; não podem ser reduzidos uns aos outros, tampouco objetivamente hierarquizados, porque todos esses bens são fundamentais e essenciais ao pleno florescimento humano. A priorização dos bens depende do raciocínio prático, da deliberação prudencial, a que Finnis (2007b, p. 97-99) denomina 
de técnica do foco. A razão prática, porém, não se dá em abstrato, apenas diante de um caso concreto, em que um bem se destaca em relação aos outros, conforme a razoabilidade prática.

Ao concluir esta exposição sintética dos bens humanos básicos, segundo a lei natural e a razão prática correlata, este texto justifica a sua hipótese fundamental de análise: o fundamento ético dos direitos humanos são os bens básicos que permitem o florescimento humano. Desse modo, pode-se investigar em que medida a dignidade da pessoa humana é protegida ou aviltada, e que direitos lhe cabem por natureza.

\section{CONCLUSÃO}

A pergunta pressuposta acerca dos direitos humanos é: Esses direitos são iguais aos demais? Partindo de uma lógica positivista é difícil encontrar uma justificativa conceitual que explique porque determinados direitos são adjetivados com o termo "humanos" enquanto outros direitos são “trabalhistas”, “contratuais”, "administrativos”, e assim por diante. A diferença está longe de ser meramente formal.

A proposição de Finnis é que o ser humano, sob determinadas condições, pode florescer, pode alcançar a sua realização. Esse florescimento não se dá de forma idêntica para todos, pois a liberdade permite a adoção de planos de vida distintos, no entanto essa realização depende de determinados bens básicos, que serão mais ou menos enfatizados, conforme as diferentes decisões das pessoas.

Se os direitos humanos são efetivamente os direitos mais básicos que a pessoa precisa ter assegurados para se desenvolver enquanto ser dotado de dignidade, então eles precisam estar assentados em uma teoria substancial do Direito. Uma teoria que não seja refém das decisões da autoridade política e que não ignore que o ser humano pode florescer. É 
necessária uma teoria que não imagine o ser humano como uma lesma movendo-se sobre o chão, e sim como um ser dotado de racionalidade e que pode alcançar sua plenitude e, então, ser feliz (eudaimonia).

\section{REFERÊNCIAS}

ARENDT, H. Eichmann em Jerusalém: um relato sobre a banalidade do mal. São Paulo: Companhia das Letras, 1999.

ARISTÓTELES. Ética a Nicômaco. 4. ed. Brasília: Editora Universidade de Brasília, 2001.

. Sobre a alma. São Paulo: WMF Martins Fontes, 2013.

BARZOTTO, L. F. Filosofia do Direito: os conceitos fundamentais e a tradição jusnaturalista. Porto Alegre: Livraria do Advogado, 2010.

CULLETON, A.; BRAGATO, F. F.; FAJARDO, S. P. Curso de direitos humanos. São Leopoldo: Unisinos, 2009.

DIAS, J. C. O direito natural no pensamento jurídico contemporâneo: John Finnis. In: DIAS, J. C.; SIMÕES, S. A. S. (Org.). Direito, políticas públicas e desenvolvimento. Rio de Janeiro: Forense; São Paulo: Método; Belém: Cesupa, 2013.

ENGELMAN, W. Direito natural, ética e hermenêutica. Porto Alegre: Livraria do Advogado, 2007.

FINNIS, J. Aquinas: Moral, Political and Legal Theory. Oxford: Oxford University Press, 1998.

. Direito Natural em Tomás de Aquino. Sua reinserção no contexto do juspositivismo analítico. Porto Alegre: Sergio Antonio Fabris Editora, 2007a.

. Lei natural e direitos naturais. São Leopoldo: Unisinos, 2007b.

Moral absolutes: Tradition, revision and truth. Washington, D. C.: The Catholic University of America Press, 1991. 
. Revisitando os fundamentos da razão prática. In: TEIXEIRA, A.; OLI-

VEIRA, E. (Orgs.). Correntes contemporâneas do pensamento jurídico. Barueri: Manole, 2010.

. Fundamentos de ética. Rio de Janeiro: Elsevier, 2012.

. Lei Natural. Por que chamar de "lei”? Por que dizê-la "natural"? In:

CANTO-SPERBER, Monique (Org.). Dicionário de ética e filosofia moral. São Leopoldo: Unisinos, 2013.

GEORGE, R. P. In defense of Natural Law. Oxford: Oxford University Press, 1999.

GREEN, L. Legal positivism. Disponível em: <http://plato.stanford.edu/ entries/legal-positivism/>. Acesso em: 10 set. 2015.

HART, H. L. A. O conceito de direito. São Paulo: Martins Fontes, 2009.

KELSEN, H. Teoria pura do direito. São Paulo: Martins Fontes, 2009.

MURPHY, M. C. Natural Law in Jurisprudence and Politics. New York: Cambridge University Press, 2006.

OLIVEIRA, E. S. Bem comum, razoabilidade prática e direito: a fundamentação do conceito de bem comum na obra de John M. Finnis. 145 p. 2002. Dissertação (Mestrado em Direito) - Faculdade de Direito da Universidade Federal do Rio Grande do Sul, Porto Alegre, 2002.

TOMÁS DE AQUINO. Suma teológica. Parte II. São Paulo: Loyola, 2009.

Recebido em: 1을 $10 / 2015$

Revisões requeridas em: 3/11/2015

Aceito em: 7/1/2016 